\title{
Low knowledge of osteoporosis and its risk factors in urban Indian adults from Pune city, India
}

\author{
Nidhi Kadam ${ }^{1}$, Shashi Chiplonkar ${ }^{1}$, Anuradha Khadilkar ${ }^{1, *}$ and Vaman Khadilkar ${ }^{2}$ \\ ${ }^{1}$ Hirabai Cowasji Jehangir Medical Research Institute, Lower Ground Floor, Jehangir Hospital, 32 Sassoon Road, \\ Pune, India - 411001: 'Jehangir Hospital, Pune, India
}

Submitted 8 February 2018: Final revision received 22 August 2018: Accepted 13 November 2018: First published online 7 January 2019

\begin{abstract}
Objective: To assess knowledge of osteoporosis and its risk factors and to explore associations between knowledge and various sociodemographic factors in Indian adults.

Design: Cross-sectional study. The Revised Osteoporosis Knowledge Test (OKT) was used to assess knowledge of osteoporosis. Four scores (OKT-total, range 0-32; OKT-exercise, range 0-20; OKT-nutrition, range 0-26; OKT-risk factors, range $0-14$ ) were generated by giving 1 point to every correct answer and 0 points for incorrect or 'not known' answers.

Setting: Tertiary-care hospital in Pune city, India.

Participants: Adults aged 40-75 years ( $n$ 477; 234 males) enrolled through voluntary routine health checks and health camps.

Results: Mean age of the study population was 54.6 (SD 9.5) years. Half the participants were aware of osteoporosis and could correctly define it. Women showed significantly higher median OKT-total and OKT-nutrition scores than men $(P<0.05)$. Those with higher education and higher socio-economic status had significantly higher scores in both men and women $(P<0.05)$. All four scores were significantly higher in both men and women who could correctly define osteoporosis $(P<0.05)$. All four scores were significantly higher in women with a family history of osteoporosis $(P<0 \cdot 05)$ but not in men $(P>0 \cdot 1)$.

Conclusions: Understanding about osteoporosis and its risk factors is low in the present cohort of Indian men and women. There is need to create awareness programmes aimed at both men and women especially targeting those with lower education, lower socio-economic status and no previous exposure to osteoporosis.
\end{abstract}

Keywords
Osteoporosis
Knowledge
Indian men
Indian women
Revised Osteoporosis Knowledge Test
Osteoporosis is a metabolic bone disease characterized by decreased bone mass and poor bone quality which leads to an increased frequency of fractures of the hip, spine and wrist. It is often called 'the silent disease' because it can progress painlessly and without any signs or symptoms. A WHO scientific report suggests that osteoporosis is a serious health risk in both men and women ${ }^{(1)}$. It is estimated that osteoporosis affects more than 200 million people worldwide $^{(2)}$. In Indian populations, the number of patients with osteoporosis is estimated to be 26 million (2003 figures), with the number projected to increase to 36 million by $2013^{(3)}$. Lifetime risk for osteoporotic fractures in women is $30-50 \%$ while in men it is $15-30 \%{ }^{(4)}$. Thus, both men and women are at risk of osteoporosis.

Although osteoporosis is a preventable disease that affects millions of people, public awareness is low ${ }^{(5)}$. Evidence suggests that knowledge and awareness of osteoporosis is one of the contributors to osteoporosis preventive behaviour $^{(6)}$. A survey conducted by the International Osteoporosis Foundation (2000) among 559 postmenopausal women in eleven countries revealed that although $93 \%$ of women acknowledge the seriousness of osteoporosis, eight out of ten did not believe they were personally at risk. In addition, $80 \%$ of women suffering from osteoporosis were unaware of their risk before diagnosis $^{(2)}$. Thus, there is a need to create awareness about the risk factors for osteoporosis and steps to improve bone health.

The first step towards increasing awareness is to assess how much is known about the disease, especially by those affected by the disease and in the general public. This is necessary to identify areas where knowledge is lacking. Studies based on other diseases have shown that knowledge about symptoms may lead to early diagnosis while information about risk factors may lead to lifestyle and behaviour modification ${ }^{(7-11)}$. Various tools are available to 
assess the knowledge of osteoporosis like the Osteoporosis Knowledge Assessment Tool (OKAT) ${ }^{(6)}$, Facts on Osteoporosis Quiz (FOOQ $)^{(12)}$, Osteoporosis Questionnaire $(\mathrm{OPQ})^{(13)}$ and Osteoporosis Knowledge Test (OKT) ${ }^{(14)}$. The OKT is one of the most frequently used tools to assess knowledge of osteoporosis ${ }^{(15)}$ in its original format, as well as with minimal modifications addressing wording and food choices that are more familiar to the culture of the region it is used in. The Revised OKT (version 2011) has tried to address previous shortcomings by adding a few more areas based on current research ${ }^{(16)}$. Thus, the Revised OKT was used in the present study to assess the level of knowledge in Indian adults.

Existing studies using various tools to assess osteoporosis knowledge suggest a general lack of awareness about risk factors, treatment and consequences of osteoporosis $^{(17,18)}$. Most of these studies are in either postmenopausal women or paramedical staff ${ }^{(19,20)}$. Men have received very little research attention even though 20-25\% of osteoporosis fractures occur in men ${ }^{(21)}$. The few studies in men suggest an overall deficit in knowledge of osteoporosis and its risk factors ${ }^{(22,23)}$. Therefore, the aims of the present study were to assess knowledge of osteoporosis and its risk factors and to explore the association between various sociodemographic factors and knowledge of osteoporosis in Indian adults above 40 years of age.

\section{Methods}

\section{Participants}

A cross-sectional study was carried out in apparently healthy adults aged 40-75 years from October 2014 to September 2016. Inclusion criteria were age 40-75 years with no major systemic disease affecting bone health like diabetes and hyperthyroidism. From the study area of Pune city, a total of ten sites comprising hospitals, housing societies, residential areas and corporate offices were approached. Through voluntary health checks and health camps organized in these areas, a total of 2080 adults in the age group of 40-75 years were identified and approached for the study without any incentive. Of these, 1500 adults provided consent to participate in the study, from whom 900 apparently healthy adults satisfied the inclusion criteria. Using computerized random number generation, 504 adults were selected and enrolled. All individuals gave informed written consent before the commencement of the study. All 504 participants answered the self-administered study tool; however, due to a lack of complete data, twenty-seven individuals were dropped from the final analysis. A total of 477 participants with complete data were analysed for the present study.

The power of the study for the total sample size was computed to be $70 \%$ using standard deviations of OKT scores from available data in men and women ${ }^{(24)}$ with the type I error probability associated with the test being 0.05 .
Anthropometric data and sociodemographic factors Weight and height were measured in the morning with participants in light indoor clothes without shoes. Weight was measured on an electronic digital scale to the nearest $0 \cdot 1 \mathrm{~kg}$ (Libra Industries, Mumbai, India) and standing height was measured using a portable stadiometer (Leicester Height Meter, Child Growth Foundation, London, UK; range $60-207 \mathrm{~cm}$ ).

Each participant completed a validated structured questionnaire on sociodemographic factors ${ }^{(25)}$ such as educational status, total monthly family income and family history of osteoporosis. Additionally, data were recorded on the correct definition of osteoporosis by the participants. If they were able to correctly define osteoporosis as 'weakening of bones or loss of calcium from bones', they were said to be aware of osteoporosis as a disease.

\section{Knowledge assessment}

The Osteoporosis Knowledge Test (Revised OKT; adapted to Indian conditions) was used to assess knowledge in the study cohort. The OKT was developed in 1991 by Kim et l $^{(14)}$ and was revised by Gendler et $^{\left(1 l^{(1)}\right.}{ }^{(1)}$ in 2015. It is a thirty-two-item tool consisting of two subscales: OKTexercise, which has twenty items; and OKT-nutrition, which is made up of twenty-six items. The two scales share fourteen common items which measure an individual's knowledge of risk factors, treatment and screening test for osteoporosis. This third subscale was named OKT-risk factors (OKT-RF). The OKT-total score consists of a total of scores on OKT-exercise, OKT-nutrition, and questions on risk factors, treatment and screening test for osteoporosis.

All questions were multiple choice. All correct answers were scored 1 while all incorrect or 'don't know' responses were scored 0 . The OKT-total score ranged from a minimum of 0 to a maximum of 32, the OKT-exercise subscale score ranged from a minimum of 0 to a maximum of 20, the OKT-nutrition subscale ranged from a minimum of 0 to a maximum of 26 and the OKT-RF subscale ranged from a minimum of 0 to a maximum of 14 .

The original thirty-two-item Revised OKT demonstrated internal consistency (total scale Kuder-Richardson$20=0 \cdot 85$, nutrition subscale $=0 \cdot 83$, exercise subscale $=$ $0 \cdot 81$. Test-retest analysis resulted in a Pearson correlation coefficient of $0 \cdot 87^{(16)}$. The adapted OKT questionnaire (as per Indian conditions) was tested on an independent sample of twenty-five adults. These twenty-five individuals included in the reliability analysis were similar in sociodemographic profile to those included in the actual sample. Test-retest reliability of these measures was high (intraclass correlation coefficient, $r=0.85, P<0.01$ for OKT-total; $r=0.79, P<0.01$ for OKT-exercise and OKT-nutrition).

\section{Statistical analysis}

Analyses were performed using the statistical software package SPSS for Windows version 16.0. All variables 
were tested for normality using the one-sample Kolmogorov-Smirnov test before any statistical comparisons were made. Data are presented as mean with standard deviation for normally distributed variables and as median with interquartile range for non-normally distributed variables. Differences between men and women with respect to variables like age were tested using Student's $t$ test for normally distributed variables. Differences between men and women with respect to OKT scores were tested using the Mann-Whitney $U$ test since the scores were nonnormally distributed. The $\chi^{2}$ test was used to test differences between categorical variables with respect to education, income categories, family history of osteoporosis, knowledge of osteoporosis and gender. To test the statistical significance of the difference in various categories of income, education and knowledge scores between two or more groups, the Mann-Whitney $U$ test and KruskalWallis test, respectively, was applied. $P$ values less than 0.05 were considered statistically significant.

\section{Results}

There was no significant difference in mean age between men and women (55.0 (SD 10.4) v. 54.1 (SD 8.6) years, $P>0 \cdot 1$; Table 1). A significantly higher percentage of women were obese compared with men $(P<0 \cdot 05)$. The two groups showed no significant differences with respect to education and total monthly family income, indicating that they belonged to similar socio-economic groups and were on a par $(P>0 \cdot 1)$. The percentage of men and women reporting a positive family history of osteoporosis was similar $(P>0 \cdot 1)$. However, a higher percentage of women had heard of osteoporosis as a disease and could correctly define it compared with men $(P<0 \cdot 05)$. A higher percentage of participants with a family history of osteoporosis $(61 \%)$ were aware of osteoporosis as a disease and could correctly define it compared with $44 \%$ who had no family history of osteoporosis $(P<0.05)$, indicating a significant positive association between those who had a family history of osteoporosis and those who were aware of osteoporosis as a disease.

\section{Participants' responses to the osteoporosis knowledge test}

Participants' responses to the thirty-two-item revised and adapted OKT are described below. Broadly, the questions were divided into three categories.

\section{Risk factors, diagnosis and treatment for osteoporosis}

Significantly more women than men could correctly identify risk factors for osteoporosis like low intake of dairy products, menopause, surgical removal of ovaries, family history of osteoporosis and being old $(P<0 \cdot 05)$. In comparison, risk factors like smoking and alcohol consumption were correctly identified as risk factors by more men than women $(P<0 \cdot 05)$. Fifty-one per cent of both men and women recognized being of Asian origin as a risk factor for osteoporosis. Being overweight was incorrectly identified as being a risk factor for osteoporosis by more than $90 \%$ of both men and women. The majority of participants incorrectly identified 'childhood' as the best time to build up bones, while less than $50 \%$ participants could identify dual-energy X-ray absorptiometry as the main diagnostic tool for osteoporosis.

\section{Knowledge of the importance of exercise}

More than $60 \%$ of participants recognized the importance of at least $30 \mathrm{~min}$ of moderate exercise daily for at least 5 $\mathrm{d} /$ week. More than $50 \%$ of participants were able to identify correctly brisk walking and aerobic dancing as activities promoting bone health, while only 8-12\% participants correctly identified weightlifting as beneficial in preventing osteoporosis.

Knowledge of the importance of calcium and vitamin D A higher percentage of women could correctly identify sources of $\mathrm{Ca}$ compared with men $(P<0 \cdot 05)$. Ice cream as a source of $\mathrm{Ca}$ was not recognized by the majority (77\%) of participants. Only $10 \cdot 4 \%$ of men and $10.6 \%$ of women participants were able to correctly identify the appropriate daily Ca requirement for adults while a higher percentage of men (61\%) could give the correct reason for taking Ca supplements compared with women $(45 \% ; P<0.05)$. A higher percentage of women identified vitamin $\mathrm{D}$ as the vitamin required for $\mathrm{Ca}$ absorption as well as sunlight being the main source of vitamin D compared with men $(P<0 \cdot 05)$. Very few participants $(5-7 \%)$ could correctly choose the daily recommendation for vitamin $\mathrm{D}$ for adults.

\section{Comparison of knowledge scores between men and women}

To sum up, the four OKT scores, namely OKT-total, OKTexercise, OKT-nutrition and OKT-RF, were compared between men and women (Table 1). Significantly higher OKT-total and OKT-nutrition scores were observed in women than men $(P<0 \cdot 05)$. No significant difference was observed between men and women for OKT-exercise and OKT-RF scores $(P>0 \cdot 1)$. Of the maximum achievable score, median OKT-total, OKT-exercise, OKT-nutrition and OKT-RF scores were 45.0, 50.0, 43.0 and $61 \cdot 8 \%$ in men and $47 \cdot 8,50 \cdot 5,47 \cdot 3$ and $64.5 \%$ in women, respectively, indicating low knowledge of osteoporosis.

\section{Participants' level of knowledge of osteoporosis}

The correct scores expressed as a percentage were divided into three groups as per the classification used by Vered et al. ${ }^{(26)}$ to indicate the level of knowledge (Fig. 1). High level of knowledge was defined as correct score of $>80 \%$; moderate level of knowledge was defined as 
Table 1 General characteristics and osteoporosis knowledge scores in the study cohort of adults (n 477) aged 40-75 years from Pune city, India, October 2014-September 2016

\begin{tabular}{|c|c|c|c|c|}
\hline \multirow[b]{2}{*}{ Variable } & \multicolumn{2}{|c|}{ Men ( $n$ 234) } & \multicolumn{2}{|c|}{ Women ( $n$ 243) } \\
\hline & Mean & SD & Mean & SD \\
\hline Age (years) & $55 \cdot 0$ & $10 \cdot 4$ & $54 \cdot 1$ & 8.6 \\
\hline Height $(\mathrm{cm})^{\star}$ & $167 \cdot 7$ & $6 \cdot 6$ & $154 \cdot 8$ & 5.9 \\
\hline \multirow[t]{2}{*}{ Weight $(\mathrm{kg})^{*}$} & $74 \cdot 1$ & $11 \cdot 8$ & 66.9 & $12 \cdot 2$ \\
\hline & \multicolumn{2}{|c|}{$\%$} & \multicolumn{2}{|c|}{$\%$} \\
\hline \multicolumn{5}{|l|}{ BMI category $(\%)^{*}$} \\
\hline Normal $\left(\mathrm{BMI} \leq 23.0 \mathrm{~kg} / \mathrm{m}^{2}\right)$ & & \multicolumn{2}{|c|}{$16 \cdot 5$} \\
\hline Overweight $\left(\overline{B M I}=23.1-28.0 \mathrm{~kg} / \mathrm{m}^{2}\right)$ & \multirow{2}{*}{\multicolumn{2}{|c|}{$\begin{array}{l}51 \cdot 9 \\
29 \cdot 4\end{array}$}} & \multirow{2}{*}{\multicolumn{2}{|c|}{$\begin{array}{l}38.0 \\
45.5\end{array}$}} \\
\hline Obese $\left(\mathrm{BMI}>28.1 \mathrm{~kg} / \mathrm{m}^{2}\right)$ & & & & \\
\hline \multicolumn{5}{|l|}{ Age group $(\%)$} \\
\hline $40-50$ years & \multicolumn{2}{|c|}{$38 \cdot 3$} & \multicolumn{2}{|c|}{39.9} \\
\hline $50-60$ years & \multicolumn{2}{|c|}{$30 \cdot 6$} & \multicolumn{2}{|c|}{$35 \cdot 4$} \\
\hline $60-75$ years & \multicolumn{2}{|c|}{$31 \cdot 2$} & \multicolumn{2}{|c|}{$24 \cdot 7$} \\
\hline \multicolumn{5}{|l|}{ Education (\%) } \\
\hline Less than graduate & \multicolumn{2}{|c|}{$27 \cdot 4$} & \multicolumn{2}{|c|}{$37 \cdot 4$} \\
\hline Graduate & \multicolumn{2}{|c|}{$48 \cdot 3$} & \multicolumn{2}{|c|}{$36 \cdot 6$} \\
\hline Postgraduate or higher & \multirow{2}{*}{\multicolumn{2}{|c|}{$24 \cdot 4$}} & \multirow{2}{*}{\multicolumn{2}{|c|}{$25 \cdot 9$}} \\
\hline Income $(\%)$ & & & & \\
\hline$<$ Rs. $20000 /$ month & \multicolumn{2}{|c|}{$16 \cdot 7$} & \multicolumn{2}{|c|}{18.5} \\
\hline Rs. $20000-40000 /$ month & \multicolumn{2}{|c|}{$20 \cdot 9$} & \multicolumn{2}{|c|}{$28 \cdot 0$} \\
\hline Rs. $40000-60000 /$ month & \multicolumn{2}{|c|}{$22 \cdot 2$} & 17 & \\
\hline > Rs. $60000 /$ month & 40 & & 36 & \\
\hline Family history of osteoporosis (\%) & & & & \\
\hline Yes & 35 & & 39 & \\
\hline No & 65 & & 60 & \\
\hline Define osteoporosis correctly $(\%)^{\star}$ & & & & \\
\hline Yes & 44 & & $5 \varepsilon$ & \\
\hline No & 55 & & 42 & \\
\hline & Median & IQR & Median & IQR \\
\hline OKT-total* & 14.5 & 6 & 16 & 6 \\
\hline OKT-exercise & 10 & 4 & 10 & 4 \\
\hline OKT-nutrition* & 12 & 5 & 13 & 6 \\
\hline OKT-RF & 7 & 4 & 7 & 4 \\
\hline
\end{tabular}

IQR, interquartile range; OKT, Revised Osteoporosis Knowledge Test (adapted to Indian conditions); OKT-total, total (exercise + nutrition + risk factors); OKT-exercise, exercise subscale; OKT-nutrition, nutrition subscale; OKT-RF, risk factors subscale.

Significant difference between men and women: ${ }^{*} P<0.05$.

correct score of 60-80\%; and low level of knowledge was defined as correct score of $<60 \%$. Only $0 \cdot 4-3.7 \%$ of participants showed a high level of knowledge, 12-33\% showed average knowledge, while the majority (>64\%) of participants showed a low level of knowledge.

\section{Association of studied variables with knowledge scores}

To understand the role of certain sociodemographic factors on the level of osteoporosis knowledge, the associations of age, education and socio-economic status based on income with median scores were assessed. Since the study population was comparable with respect to their age group distribution, educational status and income categories, pooled analysis for men and women is reported in Table 2.
No association between increasing age and OKT scores (total, exercise, nutrition and risk factor) was observed in the study cohort $(P>0 \cdot 1)$. All four OKT scores were observed to be significantly higher with increasing educational status $(P<0 \cdot 05)$. Medians of all four scores were significantly lower in the 'less than graduate' group compared with both 'graduate' and 'postgraduate or higher' groups $(P<0 \cdot 05)$. No significant difference in scores was observed between higher educational groups ('graduate' and 'postgraduate or higher'; $P>0 \cdot 1$ ). Total family monthly income was divided into four groups. Significantly lower scores were observed for the lowest category ('less than Rs. $20000 /$ month') compared with the other three income groups $(P<0.05)$. No significant difference in scores was observed with further increasing income categories $(P>0 \cdot 1)$. 


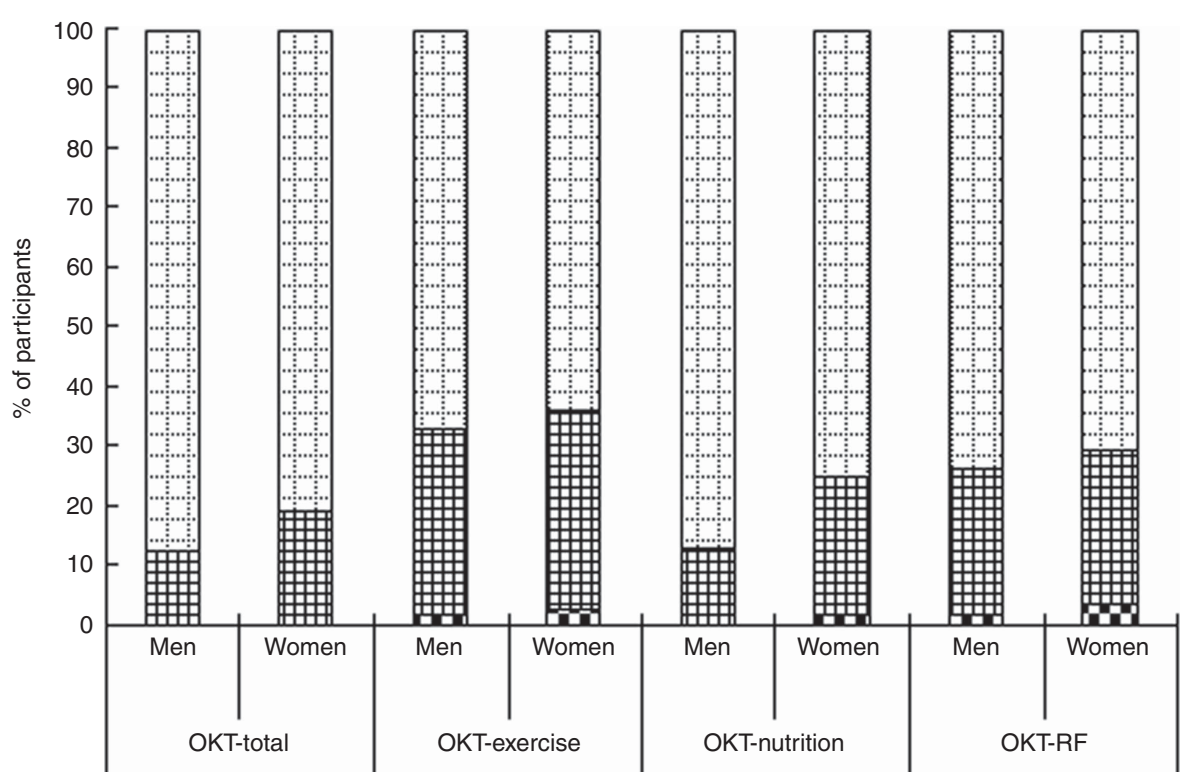

Fig. 1 Level of osteoporosis knowledge ( $\square$, low; $\boxplus$, moderate; $\boxplus$, high) in the study cohort of adults ( $n$ 477; 234 men, 243 women) aged 40-75 years from Pune city, India, October 2014-September 2016 (OKT, Revised Osteoporosis Knowledge Test (adapted to Indian conditions); OKT-total, total (exercise + nutrition + risk factors); OKT-exercise, exercise subscale; OKT-nutrition, nutrition subscale; OKT-RF, risk factors subscale).

Table 2 Association of age and sociodemographic variables with osteoporosis knowledge scores in the study cohort of adults ( $n$ 477; 234 men, 243 women) aged $40-75$ years from Pune city, India, October 2014-September 2016

\begin{tabular}{|c|c|c|c|c|c|c|c|c|}
\hline \multirow[b]{2}{*}{ Variable } & \multicolumn{2}{|c|}{ OKT-total } & \multicolumn{2}{|c|}{ OKT-exercise } & \multicolumn{2}{|c|}{ OKT-nutrition } & \multicolumn{2}{|c|}{ OKT-RF factors } \\
\hline & Median & IQR & Median & IQR & Median & IQR & Median & IQR \\
\hline \multicolumn{9}{|l|}{ Age group } \\
\hline $40-50$ years & 15 & 5 & 10 & 4 & 12 & 5 & 7 & 4 \\
\hline $50-60$ years & 15 & 6 & 10 & 4 & 12 & 6 & 7 & 4 \\
\hline $60-75$ years & 15 & 6 & 10 & 4 & 12 & 6 & 7 & 4 \\
\hline \multicolumn{9}{|l|}{ Education } \\
\hline Less than graduate & 13 & 6 & 9 & 4 & 10 & 5 & 6 & 3 \\
\hline Graduate & $16^{*}$ & 6 & $11^{*}$ & 4 & $13^{*}$ & 5 & $7^{*}$ & 4 \\
\hline Postgraduate or higher & $17^{*}$ & 6 & $11^{*}$ & 4 & $14^{*}$ & $5 \cdot 5$ & $8^{*}$ & 4 \\
\hline \multicolumn{9}{|l|}{ Income } \\
\hline < Rs. $20000 /$ month & 12.5 & $5 \cdot 5$ & 8 & 5 & 10 & $5 \cdot 25$ & 6 & 4 \\
\hline Rs. $20000-40000 /$ month & $15^{\star}$ & 6 & 10 & 4.25 & $12^{*}$ & 5 & 7 & 4 \\
\hline Rs. $40000-60000 /$ month & $17^{*}$ & 6 & $11^{*}$ & 3 & $13^{*}$ & 5 & $7^{*}$ & 3 \\
\hline$>$ Rs. $60000 /$ month & $17^{*}$ & 6 & $11^{*}$ & 4 & $13^{*}$ & 5 & $7^{*}$ & 3 \\
\hline
\end{tabular}

OKT, Revised Osteoporosis Knowledge Test (adapted to Indian conditions); OKT-total, total (exercise + nutrition + risk factors); OKT-exercise, exercise subscale; OKT-nutrition, nutrition subscale; OKT-RF, risk factors subscale; IQR, interquartile range.

Significantly different from the reference category: ${ }^{*} P<0.05$ (for education, reference category is 'less than graduate'; for income, reference category is '<Rs. $20000 /$ month').

Since a significantly higher number of women had heard of osteoporosis and could correctly define it, men and women were analysed separately to see the effect of awareness of osteoporosis as a disease on individual OKT scores (Table 3). Analysis revealed that for both men and women, significantly higher scores (OKT-total, OKT-exercise, OKT-nutrition and OKT-RF) were observed for those who were aware of osteoporosis as a disease compared with those who had never heard of osteoporosis $(P<0.05)$.

Further, although no significant differences were observed between men and women with respect to family history of osteoporosis, significantly higher scores were observed in women who had reported a family history of osteoporosis $(P<0 \cdot 05)$. In men, however, the median scores were similar in the two groups (with or without a family history of osteoporosis, $P>0 \cdot 1$; Table 3 ).

\section{Discussion}

In the present cross-sectional study in Indian adults above 40 years of age, results indicate low levels of knowledge 
Table 3 Median osteoporosis knowledge scores, by gender, family history of osteoporosis and awareness, in the study cohort of adults ( $n$ 477) aged 40-75 years from Pune city, India, October 2014-September 2016

\begin{tabular}{|c|c|c|c|c|c|c|c|c|}
\hline & \multicolumn{2}{|c|}{ OKT-total } & \multicolumn{2}{|c|}{ OKT-exercise } & \multicolumn{2}{|c|}{ OKT-nutrition } & \multicolumn{2}{|l|}{ OKT-RF } \\
\hline & Median & IQR & Median & IQR & Median & IQR & Median & IQR \\
\hline \multicolumn{9}{|l|}{ Men $(n$ 234) } \\
\hline Family history of osteoporosis & 14 & 6 & 10 & 4 & 11 & $5 \cdot 5$ & 7 & 3.5 \\
\hline No family history of osteoporosis & 15 & 7 & $10 \cdot 5$ & 4.25 & 12 & 6 & 7 & 4 \\
\hline Heard of osteoporosis & $17^{*}$ & 6.75 & $12^{*}$ & 5.75 & $13 \cdot 5^{\star}$ & 5 & $8^{*}$ & 4 \\
\hline Never heard of osteoporosis & 13 & 6 & 10 & 3 & 10 & 5 & 6 & 3 \\
\hline \multicolumn{9}{|l|}{ Women $(n 243)$} \\
\hline Family history of osteoporosis & $17^{*}$ & 5.5 & $11^{*}$ & 4 & $14^{*}$ & 5 & $8^{(*)}$ & 3 \\
\hline No family history of osteoporosis & 15 & 6 & 10 & 4 & 12 & 6 & 7 & 4 \\
\hline Heard of osteoporosis & $18^{*}$ & 5 & $11^{*}$ & 4 & $14^{*}$ & 4.25 & $8^{*}$ & 4 \\
\hline Never heard of osteoporosis & 14 & 6 & 10 & 5 & 10 & 5 & 6 & 3 \\
\hline
\end{tabular}

OKT, Revised Osteoporosis Knowledge Test (adapted to Indian conditions); OKT-total, total (exercise + nutrition + risk factors); OKT-exercise, exercise subscale; OKT-nutrition, nutrition subscale; OKT-RF, risk factors subscale; IQR, interquartile range.

In men and women separately, median score was significantly different between the two groups (family history of osteoporosis $v$. no family history of osteoporosis; heard of osteoporosis $v$. never heard of osteoporosis):

(*) $P<0.1,{ }^{*} P<0.05$.

about osteoporosis in the majority $(>64 \%)$ of the participants. Both men and women had low scores in total as well as on exercise, nutrition and knowledge of risk factors of osteoporosis. However, women scored better in the overall knowledge score (OKT-total) as well as nutritional knowledge (OKT-nutrition) compared with men. All scores were positively associated with education, socioeconomic status (as defined by income categories) and positive family history of osteoporosis.

Forty-four per cent of men and $58 \%$ of women in the present study were aware of osteoporosis as a disease and could correctly define it. Similar results have been reported in women from Singapore $(58 \%$ had heard of osteoporosis) and Turkey $(60 \%$ had heard of osteoporosis $)^{(27,28)}$. A study by Juby and Davis in men showed only $43 \%$ of men could correctly define osteoporosis ${ }^{(29)}$, which is close to our results. This highlights the fact that almost $50 \%$ of adults had never heard of osteoporosis and therefore may be unaware of its symptoms or risk factors.

Individual knowledge scores (OKT-total, OKT-exercise, OKT-nutrition and OKT-RF) indicated that women could correctly identify risk factors which were related to women's reproductive system, while factors like smoking and alcohol consumption were correctly identified by more men. Similarly, a higher percentage of women than men could correctly answer nutritional knowledge questions, perhaps because in India women are responsible for taking care of the nutritional requirements of the family and are more involved in activities like cooking. Further, osteoporosis has often been labelled a postmenopausal disease and therefore is believed to affect a greater number of women than men. A systematic review by Gaines and Marx (2010) on older men's knowledge of osteoporosis revealed that men have less knowledge than women. The review also highlighted the fact that the majority of men have limited understanding of the osteoporosis disease process, prevention and risk factors. Further, men do not believe that they are susceptible to osteoporosis but believe that osteoporosis is not a serious disease $^{(15)}$. Thus, it is important that bone health promotional campaigns which are aimed mostly at postmenopausal women should expand their focus to include men, especially in India, in order to improve their knowledge and bone health.

Level of osteoporosis knowledge indicated that the majority of participants in the present study (both men and women) had inadequate knowledge of osteoporosis and only $0.4-3.7 \%$ participants showed an acceptable level of knowledge (>80\% correct answers), as defined by Palacious et $a l{ }^{(30)}$. Similar results have been reported by Doheny et al. in men and women above 50 years of age using the $\mathrm{OKT}^{(31)}$. Most participants in the present study belonged to middle- and high-income categories and had completed their graduation. Therefore, if in these individuals with better education and socio-economic status the knowledge is so low, there is a need for efforts to focus on increasing osteoporosis awareness in the Indian population.

Osteoporosis knowledge scores have been shown to be positively associated with sociodemographic factors. Our results indicate a positive association between knowledge scores and education level as well as total family monthly income. A similar association between education, socioeconomic status and knowledge scores has been reported by other studies ${ }^{(32-34)}$. The positive influence of sociodemographic factors indicates that education and socioeconomic status are important factors that should be considered while designing osteoporosis awareness programmes, especially in India. 
The present study, although providing insight in the field of Indian men and women's knowledge of osteoporosis and its risk factors, may be limited in scope by certain facts. First, the study was carried out in a single geographic location in Western India and the results may vary in other regions of the country. Second, the study was cross-sectional and assessed adults who had access to a tertiary-care hospital. It is possible that the awareness and knowledge may be even lower among groups who do not have access to the health-care system. Further, the socio-economic status of present study's participants showed that the majority were from the high-income group. Therefore, the results may not apply to the Indian population in general. However, our study stresses the need to assess knowledge and create awareness across all socioincome groups. This would help in identifying specific areas for making osteoporosis education policies.

\section{Conclusion}

In conclusion, understanding of osteoporosis and its risk factors is low in the present cohort of Indian men and women. There is need to create awareness programmes aimed at both men and women, targeting those with lower education, low socio-economic status and no previous exposure to osteoporosis.

\section{Acknowledgements}

Acknowledgements: The authors would like to thank Dr Elles Gendler for permission to use the Revised Osteoporosis Knowledge Test. Financial support: This work was supported by the Women Scientist Scheme under Department of Science and Technology, Government of India. The funder had no role in the design, analysis or writing of this article. Conflict of interest: None. Authorship: S.C. and A.K. designed the research; N.K. conducted the research; S.C., A.K., N.K. and V.K. analysed the data; N.K., S.C., A.K. and V.K. were involved in writing the manuscript; A.K. had primary responsibility for the final content; all authors read and approved the final manuscript. Ethics of buman subject participation: This study was conducted according to the guidelines laid down in the Declaration of Helsinki and all procedures involving human subjects were approved by the ethics committee at Jehangir Clinical Development Center, Pune (India). Written informed consent was obtained from all individual participants included in the study.

\section{References}

1. World Health Organization (2004) Scientific Group on the Assessment of Osteoporosis at Primary Health Care Level. Geneva: WHO.

2. International Osteoporosis Foundation (2017) Facts and statistics. https://www.iofbonehealth.org/facts-statistics (accessed January 2017).
3. Osteoporosis Society of India (2003) Action Plan Osteoporosis: Consensus Statement of an Expert Group. New Delhi: Osteoporosis Society of India.

4. Randell A, Sambrook PN, Nguyen TV et al. (1995) Direct clinical and welfare costs of osteoporotic fractures in elderly men and women. Osteoporos Int 5, 427-432.

5. Abushaikha L, Omran S \& Barrouq L (2009) Osteoporosis knowledge among female school students in Jordan. East Mediterr Health J 15, 906-911.

6. Winzenberg TM, Oldenburg B, Frendin S, et al. (2003) The design of a valid and reliable questionnaire to measure osteoporosis knowledge in women: the Osteoporosis Knowledge Assessment Tool (OKAT). BMC Musculoskelet Disord 24, 4-17.

7. Sheikh I \& Ogden J (1998) The role of knowledge and beliefs in help seeking behavior for cancer: a quantitative and qualitative approach. Patient Educ Couns 35, 35-42.

8. Yardley C, Glover C \& Allen-Mersh TG (2000) Demographic factors associated with knowledge of colorectal cancer symptoms in a UK population-based survey. Ann $R$ Coll Surg Engl 82, 205-209.

9. de Nooijer J, Lecher I \& De Vries H (2001) A qualitative study on detecting cancer symptoms and seeking medical help: an application of Andersen's model of total patient delay. Patient Educ Couns 42, 145-157.

10. Gupta A \& Thomas P (2002) Knowledge of stroke symptoms and risk factors among at-risk elderly patients in the UK. Int J Clin Pract 56, 634-637.

11. Werner P (2003) Knowledge about symptoms of Alzheimer's disease: correlates and relationship to help-seeking behavior. Int J Geriatr Psychiatry 18, 1029-1036.

12. Ailinger RL, Lasus H \& Braun MA (2003) Revision of the facts on osteoporosis quiz. Nurs Res 52, 198-201.

13. Berarducci A, Lengacher CA \& Keller R (2002) The impact of osteoporosis continuing education on nurses' knowledge and attitudes. J Contin Educ Nurs 33, 210-216.

14. Kim K, Horan M \& Gendler P (1991) Osteoporosis Knowledge Tests, Osteoporosis Health Belief Scale, and Osteoporosis Self-Efficacy Scale. Allendale, MI: Grand Valley State University.

15. Gaines JM \& Marx KA (2011) Older men's knowledge about osteoporosis and educational interventions to increase osteoporosis knowledge in older men: a systematic review. Maturitas 68, 5-12.

16. Gendler PE, Coviak CP, Martin JT et al. (2015) Revision of the Osteoporosis Knowledge Test: reliability and validity. West J Nurs Res 37, 1623-1643.

17. Spencer SJ (2007) Lack of knowledge of osteoporosis: a multi-centre, observational study. Scott Med J 52, 13-16.

18. Pande K, Pande S, Tripathi S et al. (2005) Poor knowledge in learned Indian women. $J$ Assoc Physicians India 53, 433-436.

19. de Silva REE, Haniffa MR, Gunathillaka KDK et al. (2014) A descriptive study of knowledge, beliefs and practices regarding osteoporosis among female medical school entrants in Sri Lanka. Asia Pac Fam Med 13, 15.

20. Chen IJ, Yu S, Wang TF et al. (2005) Knowledge about osteoporosis and its related factors among public health nurses in Taiwan. Osteoporos Int 16, 2142-2148.

21. Werner P (2005) Knowledge about osteoporosis: assessment, correlates and outcomes. Osteoporos Int 16, 115-127.

22. Shawa H, Favela E \& Diaz J (2011) Knowledge of osteoporosis among men in the primary care setting. South Med J 104, 584-588.

23. Chaudhary D \& Khan YA (2016) Osteoporosis awareness in Indian men: a cross sectional study. Int J Sci Res 5, 254.

24. Ford MA, Bass M, Zhao Y et al. (2011) Osteoporosis knowledge, self-efficacy, and beliefs among college students in the USA and China. J Osteoporos 2011, 729219. 
25. Kumar N, Gupta N \& Kishore J (2012) Kuppuswamy's socioeconomic scale: updating income ranges for the year 2012. Indian J Public Health 56, 103-104.

26. Vered I, Werner P, Shemy G et al. (2008) Nurses' knowledge and perceptions about osteoporosis: a questionnaire survey. Int J Nurs Stud 45, 847-854.

27. Saw SM, Hong CY, Lee J et al. (2003) Awareness and health beliefs of women towards osteoporosis. Osteoporos Int 14, 595-601.

28. Gemalmaz A \& Oge A (2008) Knowledge and awareness about osteoporosis and its related factors among rural Turkish women. Clin Rheumatol 27, 723-728.

29. Juby AG \& Davis P (2001) A prospective evaluation of the awareness, knowledge, risk factors and current treatment of osteoporosis in a cohort of elderly subjects. Osteoporos Int 12, 617-622
30. Palacios S, Sánchez-Borrego R, Neyro JL et al. (2009) Knowledge and compliance from patients with postmenopausal osteoporosis treatment. Menopause Int 15, 113-119.

31. Doheny MO, Sedlak CA, Estok PJ et al. (2007) Osteoporosis knowledge, health beliefs, and DXA T-scores in men and women 50 years of age and older. Orthop Nurs 26, 243-250.

32. Riaz M, Abid N, Patel J et al. (2008) Knowledge about osteoporosis among healthy women attending a tertiary care hospital. J Pak Med Assoc 58, 190-194.

33. Alexandraki KI, Syriou V, Ziakas PD et al. (2008) The knowledge of osteoporosis risk factors in a Greek female population. Maturitas 59, 38-45.

34. Janiszewska M, Kulik T, Dziedzic MA et al. (2015) Chosen risk factors for osteoporosis and the level of knowledge about the disease in peri- and postmenopausal women. Prz Menopauzalny 14, 27-34. 